\title{
Speaking the same language: Navigating information-sharing in the youth justice sphere
}

Joanna Appleby ${ }^{1}$, Matthew Shepherd ${ }^{2}$ and Barbara Staniforth ${ }^{3}$

\begin{abstract}
INTRODUCTION: Qualitative research was undertaken to explore professionals' experiences of cross-sector information-sharing about the mental health needs of young people in youth justice residences in Aotearoa New Zealand.

METHODS: Eight focus groups $(N=36)$ were conducted across Aotearoa New Zealand. Half of these were with case leaders from each of the four Oranga Tamariki - Ministry for Children - youth justice residences. The other half were with youth forensic service (YFS) clinicians who provide mental health services in each youth justice residence.
\end{abstract}

FINDINGS: The findings showed positive cross-sector relationships, despite a lack of policy around information-sharing in this context. Themes from case leaders included the practicalities of the residential environment (including restriction on young people's freedoms and managing group safety), and case leaders' brokerage role between competing theoretical frameworks in residence. Themes from YFS clinicians included the importance of cross-sector information-sharing for the assessment and discharge phases of mental health input. Overall themes included the impact of relationships on information-sharing, and the importance of including residential care team staff within information-sharing practices. A proposed model of information-sharing in this context has been developed.

CONCLUSIONS: Effective information-sharing in youth justice residences is imperative to ensure that young people receive appropriate mental health input in residences, and that residence staff are supported to provide the best care for these young people. Social work has an important role within information-sharing practices with use of systems theory, translation of clinical jargon, and advocacy for the needs of young people involved in multiple systems.

KEYWORDS: information-sharing; communication; interagency; youth justice residences; youth forensic

There has been increasing understanding of the importance of improved interagency information-sharing about vulnerable young people, both in Aotearoa New Zealand, and internationally (Laming, 2003; Ministry of Health, 2011). One such population are young people in youth justice residences. Youth justice residences provide residential services for young people aged 12-17 whose offending poses a risk to themselves or others, and is seen as an intervention of last resort (Ministry of Social Development, 2016.
${ }^{1}$ Auckland District Health Board

${ }^{2}$ Massey University

${ }^{3}$ The University of Auckland
AOTEAROA

NEW ZEALAND SOCIAL WORK 31(1), 59-71.

CORRESPONDENCE TO: Joanna Appleby joanna.appleby@gmail.com 
There are four youth justice residences in Aotearoa New Zealand, which are managed by Oranga Tamariki - the Ministry for Children. The residences are located in Auckland, Rotorua, Palmerston North and Christchurch. Each young person will have a case leader, who is usually a social worker, and is responsible for needs assessment and developing a care plan, alongside ongoing collaboration with the young person's youth justice social worker. The young people are placed into locked units staffed by a rotating shift of residential youth workers; they have a shared living area and separate bedrooms.

Youth justice residences are filled with young people who face a number of issues. Most of the young people have experienced significant trauma, social deprivation, poverty, exposure to family violence, and disconnection from their culture (Office of the Prime Minister's Chief Science Advisor, 2018). There has been increasing acknowledgement of the overrepresentation of neurodisabilities among the young offender population in Aotearoa New Zealand, including intellectual disability, traumatic brain injuries, foetal alcohol spectrum disorder, attention-deficit hyperactivity disorder and autism spectrum disorder (Lynch, 2016).

There are also disproportionately high numbers of Māori young people in youth justice residences, who comprise $72 \%$ of all young people sentenced to Residence with Supervision (Ministry of Social Development, 2016). Reasons for this are likely to include the impact of colonisation, and the resulting socioeconomic disadvantage experienced by many Māori people in Aotearoa New Zealand, as well as identified biases against Māori within the justice system (Jones, 2016).

Internationally, young people who offend are reported to have high prevalence rates of mental health issues, between $40 \%$ and $60 \%$, with a higher severity level than the general population (Skowyra \& Cocozza, 2007). The prevalence of mental health issues is even higher for youth in secure residences, and is estimated to be between $60-100 \%$ (The Werry Centre, 2009). Recent research into prevalence rates in Aotearoa New Zealand found that nearly $80 \%$ of young people in a youth justice residence had elevated scores on a mental health screening tool, the Massachusetts Youth Screening Instrument (second version, MAYSI-2), with higher rates for females and for Māori and Pacific Island subgroups (McArdle \& Lambie, 2018).

Youth forensic services (YFS) have been developed in response to this identified need for mental health services for young people who have offended (The Werry Centre, 2009). YFS teams visit youth justice residences to provide mental health assessment and treatment, while Oranga Tamariki manages the day-to-day care of the young people within the residence.

Within this context of increased emphasis on interagency information-sharing, Oranga Tamariki hosting external YFS providers, and young people presenting with high needs, there has been little in the way of an information-sharing policy. There have been no guidelines on how Oranga Tamariki and YFS teams should share information with each other, despite the significant need for effective and safe information-sharing within a residential environment.

A qualitative research project was undertaken as a part of the first author's Master of Social Work to explore the expectations of Oranga Tamariki case leaders and YFS clinicians about the function, form and content of information-sharing with each other, to identify factors that contribute to effective information-sharing, and to develop a proposed model of information-sharing for this context.

\section{Literature}

Policy and literature clearly support the idea of collaboration within youth justice systems (Lambie, Krynen, \& Best, 2016; Office of the Children's Commissioner, 2015; Skowrya 
\& Cocozza, 2007). Collaboration is deemed important due to the number of services involved with these young people, as well as the violence risks associated with offending, and the high rates of mental health issues which may remain undiagnosed for some time.

There has been no research into the experience of the young offenders themselves regarding information-sharing. However, there has been some more general research internationally into the perspectives of parents and young people about sharing mental health information with other sectors which supported the idea of increased information-sharing (Wilson, Pillay, Kelly, \& Casey, 2015).

The only Aotearoa New Zealand research into client perspectives of information-sharing was related to experiences of sharing financial information between government agencies (National Research and Evaluation Unit, 2013). Concerns were raised by participants about sharing of inaccurate information, perpetuating a false understanding of an individual. Māori participants spoke about the concept of personal information being a part of who they are, but when it is shared, it no longer belongs to them, and this may be disempowering for Māori. Māori participants also highlighted culturally sensitive topics, including historic records, the significance of hand-written information, and information about deceased family members, and suggested that there be greater sensitivity when sharing this information across agencies.

There is no previous research examining enabling factors for information-sharing within youth justice residences. However, there were a number of studies examining collaborative efforts between a range of sectors, and barriers and enablers to effective information-sharing between organisations. There were several key information-sharing and collaboration enablers identified, including leadership and management support of collaborative efforts (Agranoff \& McGuire, 2001), positive individual relationships underpinning information-sharing practices (Mills, Meek, \& Gojkovic, 2012), co-location of services to enhance informal discussion (Gask, 2005), clear policy about information-sharing (Bai, Wells, \& Hillemeir, 2009) and shared information systems (Gil-Garcia \& Sayogo, 2016). Privacy concerns were identified as a barrier to information-sharing, particularly where policy was unclear (Anderson, 2005; Richardson \& Asthana, 2006).

\section{Method}

Data for this article were obtained as part of a Master of Social Work research project. The study was approved by The University of Auckland Human Participants Ethics Committee, the Oranga Tamariki Research Access Committee and the Auckland District Health Board Research Office.

There were four research questions:

What are the expectations of Oranga Tamariki case leaders about the function, form and content of information-sharing with YFS?

What are the expectations of YFS about the function, form and content of informationsharing with Oranga Tamariki case leaders?

What factors contribute to effective information-sharing in youth justice residences?

What would be a model of informationsharing in youth justice residences that meets the needs of both sectors?

\section{Participants}

Given that the research questions were regarding the experiences of informationsharing between Oranga Tamariki and YFS teams, participants were case leaders (mostly social workers) from each youth justice residence, and youth forensic service (YFS) clinicians (including social workers) 
who provided services at each residence. Focus groups were held with participants from each group from each of the four youth justice residences (eight in total). The total number of participants across the eight focus groups was 36, with a fairly even split between case leaders and YFS clinicians.

\section{Procedure}

The data collection method involved focus groups, which were held at each of the four youth justice residences, and each of the four YFS teams providing services at each residence. Focus groups were chosen in order to get a wide range of data, and to explore organisational approaches to informationsharing. There were additional benefits, including providing a more relaxed setting to ask about standard practice and cross-sector frustrations, and to encourage solution-focused group discussion (Davidson \& Tolich, 2003).

Focus groups were held on-site at the participants' place of work. Māori cultural rituals of engagement were used, including provision of kai and engagement in whakawhānaungatanga processes. The decision to seek Māori consultation and to include these processes occurred in recognition of the researcher's commitment to bicultural practice, and in acknowledgement of the large number of Māori young people in youth justice residences. There was also a commitment to ensuring that research aligned with bicultural obligations and was ethical.

There was a high degree of participation in the research, with all Aotearoa New Zealand youth justice residences and their YFS teams agreeing to participate. Within each team there were good levels of individuals choosing to participate, with 18 out of 25 youth justice residence case leaders opting to be involved, and 18 out of 28 YFS clinicians. That translated to $72 \%$ of all youth justice case leaders, and $64 \%$ of all YFS clinicians working in a residence. Overall there was a $68 \%$ participation rate for all potential participants in Aotearoa New Zealand.

\section{Analysis}

Following the completion of all focus groups, thematic analysis supported by NVivo11 software was used to analyse the data, with themes identified from the inductive coding of the focus group transcripts (Braun \& Clarke, 2006).

Analysis of the data was initially completed for the four residential case leader focus groups, and then for the four youth forensic service focus groups, in order to find themes distinct to each sector. The data were then analysed at an overall level of the eight services, looking for common themes across both sectors within the four regions. The aim of this approach was to capture an overview of the experiences of each sector (YFS and Oranga Tamariki), and to work towards a national model of information-sharing. Participants consented to the research on the understanding that their unique responses and team responses would not be identifiable, and that the research was solution-focused, rather than evaluative.

\section{Ethical issues}

The researcher is employed in the Auckland YFS team, and has been providing mental health services in the Auckland youth justice residence since 2011. There were benefits to being a practitioner researcher (Shaw \& Lunt, 2011). These including greater ease of access to participants, perceived legitimacy in the field, and implied understanding of the day-to-day work. However, there were also significant ethical issues to navigate, including perceived conflicts of interest and the researcher's dual roles (Lunt, Ramian, Shaw, Fouché, \& Mitchell, 2012). All ethical issues were discussed in supervision, and the two Auckland focus groups were completed by the research supervisor.

\section{Findings}

This research project explored the expectations of both youth justice residence case leaders, and youth forensic staff about information-sharing in youth justice 


\begin{tabular}{|l|l|l|}
\multicolumn{1}{c|}{ Oranga Tamariki themes } & \multicolumn{1}{|c|}{ YFS themes } & \multicolumn{1}{c|}{ Overall themes } \\
\hline $\begin{array}{l}\text { Specialised work } \\
\text { Case leader as brokers }\end{array}$ & $\begin{array}{l}\text { Assessment } \\
\text { Discharge planning }\end{array}$ & $\begin{array}{l}\text { Relationships } \\
\text { Care teams are crucial }\end{array}$ \\
\hline
\end{tabular}

residences. Within this context, case leaders (employed by Oranga Tamariki) have clinical oversight for young people in the residence. Oranga Tamariki, as a Ministry, is responsible for the safety and care of the young people within the residence. YFS clinicians are visitors in this space, coming into the residences to provide mental health services for the young people. YFS clinicians are external to the residence, and yet also have responsibilities for the mental health care of young people in the residence. In order to understand the experience of each sector, the themes from the research were identified through examining the data from each sector (Oranga Tamariki and YFS). There were six key themes from the research, as shown in Table 1, two from the Oranga Tamariki data, two from the YFS data, and two themes that spanned all the focus groups.

\section{Oranga Tamariki themes}

\section{Specialised work}

Overwhelmingly, residential case leaders reported that YFS clinicians need to understand the context of the youth justice residence, and tailor their approaches to fit the context. Case leaders spoke about the specialised nature of work in a residence. They identified that there is a higher need for information-sharing. They also requested that YFS staff are aware of the practical limits of the residence, and provide clinical recommendations that are possible to implement in a residence. Case leaders wanted YFS teams to work within the limitations of access to the young people, and to recognise that high levels of responsivity within a residential context are imperative.

Conditions like foetal alcohol, posttraumatic stress and ADHD, oppositional defiance disorder and conduct disorders and things like that. Those are quite big conditions for us [case leaders]....For the forensic team, no they are minor, but they are minor especially outside of a residential environment where a young person has got those conditions but they can go for a walk to calm down and you can use all your DBT [Dialectical Behaviour Therapy], they can use sport, they can use music because they have got some headphones.

In particular, understanding the residence regulations and the dynamics of managing a group of challenging young people were seen as areas for YFS clinicians to improve their knowledge. Case leaders gave examples of inappropriate recommendations from YFS, including young people having time alone or a particular drink before bedtime. The current resourcing and regulations within the units do not support those interventions.

\section{Case leaders as brokers}

The second theme from case leaders was about their brokerage role in the residences. The complexity of the case leader role was reflected in the focus group discussions. Case leaders spoke about the myriad of demands placed upon them from YFS, other external providers, care teams (youth workers who work directly with the young people on each unit, on rotating shifts), residence management teams, site social workers and family, along with the young people themselves. Within this, case leaders reflected on competing frameworks within youth justice residences. Many of the case leaders work within a clinical framework, valuing therapeutic input, rehabilitation, and individualised approaches. However, this clinical team is located within a residence 
that has relied on operational models, particularly from care teams. The operational framework values behaviour management, containment and risk management for the unit. Case leaders have a brokerage role in translating YFS clinical recommendations into operational frameworks that are relevant and palatable to floor staff who are concerned about group safety and behaviour management. The case leaders' brokerage role extends to also advocating for individualised approaches within a group context.

[It's a] Balancing act to be a case leader, sandwiched in the middle, pressure coming down and pressure coming up. We're in the middle, with nowhere to put it. We just have to cope with it.

\section{Youth Forensic Service themes}

\section{Assessment}

YFS clinicians identified the assessment phase as a time when greater informationsharing would be beneficial for the young person. Concerns were raised about young people entering a system of overassessment, where multiple providers are asking similar questions, with the potential of negatively impacting young people's engagement in assessment and therapeutic interventions. Many of the young people in youth justice residences have had prior involvement with mental health services across the country, including YFS teams that have completed court reports in other locations. Aotearoa New Zealand does not have a single unified mental health database, and so gathering national information has relied on young people's disclosures of previous service provision. YFS teams spoke about the lack of connection between YFS teams nationally, with little knowledge about the service model for each region.

I'm yet to see a young person that comes into residence with nothing. They've been seen by someone, they have a history, and it's that collateral information that will either help us make a decision that they don't need something, or we do see them and that information gets incorporated.

\section{Discharge planning}

The second YFS theme was regarding the difficulties associated with discharge planning for young people when they leave a youth justice residence. Most of the young people are remanded, not sentenced, in a youth justice residence, which means that they can leave whenever a judge grants them bail. This can often come as a surprise to YFS clinicians who are providing ongoing mental health treatment to young people. The other difficulty is that young people are sometimes moved between the residences, presumably to help manage group dynamics and assist with national youth justice bed configurations. This, again, is often a surprise to YFS clinicians, as well as the young people themselves. YFS clinicians expressed frustration with the lack of informationsharing from Oranga Tamariki about discharge planning, with concerns about the potential trauma of sudden goodbyes with vulnerable young people, who often have a history of poor attachment and experiences of loss, trauma and rejection. YFS clinicians recognised that this was not the fault of case leaders, and instead was representative of information-sharing in the wider youth justice context.

You are constantly trying to find out how long they are going to stay there... it is only the Judge that decides on the day...And the kids will go to court and they will have no idea whether they are coming back or not.

The additional difficulty about discharge planning identified by YFS clinicians was problematic transfers of care to community child and adolescent mental health services (CAMHS). There was a recognition that YFS services are highly responsive, with 
minimal threshold for assessment, and a wide range of mental health treatment is available to young people in youth justice residences, including individual therapy, skills groups, sensory intervention, and medication. However, there were perceptions that it was often challenging for those young people to have positive experiences with CAMHS. Possible reasons that were discussed included higher referral criteria thresholds for acceptance into CAMHS and/or young people's lack of motivation, in combination with perceived non-assertive engagement approaches by CAMHS.

\section{Overall themes}

\section{Relationships}

In looking at data about informationsharing across both sectors and in all four regions, collegial relationships were seen to be significant contributors to positive experiences of information-sharing.

Relationships were strengthened through accessible contact (answering phones and emails) as well as opportunities to meet face to face. This happened informally at the residences, as well as more formally through attendance at regular multi-agency team (MAT) meetings. MAT meetings were described as effective forums to strengthen cross-sector relationships, and to discuss information more freely.

Participants in many of the focus groups discussed high-risk cases. Management of these cases tended to either strengthen or weaken cross-sector relationships, depending on how services met the expectations of their cross-sector partner. There were positive examples given about admissions to the recently established Ngā Taiohi national adolescent forensic inpatient unit. YFS teams have brokering roles in getting young people into Ngā Taiohi, and case leaders expressed much appreciation for the work YFS teams have done to get mentally unwell young people out of residence and into Ngā Taiohi. This was seen to have strengthened cross-sector relationships.

\section{Care teams}

The final theme concerned the perspective of both sectors that the importance of care teams in information-sharing practices had often been neglected and underestimated. Care teams are made up of youth workers who have the most contact with young people in residence, often do not have formal academic qualifications, and work within an operational framework that may underestimate the impact of mental health on a young person's behaviour. Focus group participants across both sectors identified that care teams are responsible for implementing clinical recommendations, despite often coming from non-clinical backgrounds, with limited understanding of mental health. Therefore, there needed to be understanding and buy-in of clinical recommendations by the care teams in order for the recommendations to be implemented in the way that YFS clinicians intended. Failure to involve care teams in information-sharing practices leads to a high risk that clinical recommendations are not implemented, or are poorly understood.

We [YFS] pass on all our information to case leaders and more often than not it seems it doesn't filter down to the people that are actually working with them on the floor, and that is where intervention should be done... I don't know what the answer is, because there are three shifts as well... but somehow getting that information from the case leader to everyone that works with the young person would be really helpful.

Care teams also hold valuable information about young people's dayto-day functioning and behaviour. This information is often very useful for diagnostic assessments, as well as assessing the efficacy of treatment, such as medication 
for Attention-Deficit Hyperactivity Disorder (ADHD). Through the process of reflection during the focus groups, both sectors recognised the importance of care teams, while also recognising that current information-sharing practices were not generally inclusive of care teams.

\section{Factors that affect information- sharing}

From the research findings, factors that improve cross-sector information-sharing and collaboration can broadly be grouped into relationships, role clarity, training, and processes.

\section{Relationships}

Unsurprisingly in this study, the quality of cross-sector information-sharing reflects the quality of cross-sector relationships. This aligns with the literature on crosssector cooperation, which emphasises the importance of relationships (Haight, Bidwell, Marshall, \& Khatiwoda, 2014; Richardson \& Asthana, 2006).

Interestingly, there was little participant discussion about the impact of leaders and managers on information-sharing practices. This is in contrast to the literature that suggests leadership is influential on collaborative efforts (Daley, 2009). The lack of comment about leadership supports the notion that information-sharing practices are developed at the interface between case leaders and YFS, and that this is often affected by the quality of relationships between those individuals, irrespective of management approaches to cross-sector information-sharing.

The lack of relationship between the different YFS teams nationally may contribute to the paucity of information flow between each YFS team, despite seeing many of the same young people who move between residences. While there are certainly issues of different information systems among the YFS teams, the difficulties with information-sharing appear to be exacerbated by the lack of relationship between clinicians across the forensic teams, many of whom do not (yet) know each other.

\section{Role clarity}

Those teams that enjoy good cross-sector relationships tend to have clear expectations of their own role within the residence, and also understand their cross-sector partner's role. Role clarity has been identified in the literature as a factor to improve informationsharing (Cameron \& Lart, 2003). This research found that there is a reasonably good level of role clarity currently, particularly between case leaders and YFS. The two areas to improve upon are having clearer expectations about what information can and should be shared, and improving role clarity between YFS and care teams. It was suggested, by case leaders and YFS teams, that there should be more direct communication and interaction between YFS teams and care teams. There is existing research that supports the idea of having contact between mental health teams and those staff working directly with people, including in prisons (Lennox, Mason, McDonnell, Shaw, \& Senior, 2012) and schools (Rothi \& Leavey, 2006). However, this was the first research project to identify this need within a youth justice residence.

\section{Training}

Joint training was identified in the literature as a means of establishing role clarity and strengthening cross-sector relationships (Darlington, Feeney, \& Rixon, 2004). The data from this research project also supported the idea of joint training as a factor to enhance cross-sector understanding and appropriate information-sharing. In particular, YFS teams would like to provide training about mental health diagnoses, and case leaders would like to provide training to YFS teams about the residential environment.

\section{Processes}

The final category of factors to enhance information-sharing is processes. Processes 
occur at the individual level within a foundation of trusting relationships. Service-level processes include dedicated information gatherers and new admission processes. Some YFS teams have staff in dedicated roles to gather information for the assessments, and to disseminate information to stakeholders, including case leaders. Some residences have processes for gathering information about young people as soon as they are known to be arriving at a residence. This helps to get all the education, health, drug and alcohol, and mental health information gathered and prepared before a young person even arrives at the residence. These service-level processes help to ensure good information flow, with systems in place, rather than relying on individuals.

\section{Discussion}

This research set out to explore the expectations of Oranga Tamariki case leaders and YFS clinicians regarding cross-sector information-sharing about young people in youth justice residences to identify factors that enhance information-sharing, and to develop a model of information-sharing in this specific field of practice.

From case leaders' perspectives, informationsharing from YFS teams about mental health needs is vital in order to ensure that young people's needs are met in residence, and to ensure the safety of the other young people and staff. For YFS staff, the emphasis is more on information-sharing from case leaders to inform clinical assessments and therefore appropriate recommendations and treatment, and to avoid over-assessment of young people. This client-centred approach fits well with research into client experiences of cross-sector information-sharing, with frustration about repeating information to various professionals (Siraj-Blatchford \& Siraj-Blatchford, 2010).

\section{Contrast with the literature}

Previous research into Māori family perspectives on governmental information- sharing highlighted concerns about sharing culturally sensitive information, including whakapapa, and concerns about ownership of the information once it has been shared (National Research and Evaluation Unit, 2013). The concerns raised in this research project by YFS teams were less to do with culturally sensitive information, much of which is included in a mental health assessment, but about the sharing of information that may create prejudice about a whānau. This includes information about trauma and behaviour, which remain on a young person's file, and, from the perspective of YFS participants, may be inaccurate. This particular issue highlighted an issue of mistrust between some YFS teams and Oranga Tamariki as a governmental ministry, and how information is used once a young person has left the youth justice residence. While there appear to be good levels of trust between YFS and case leaders, YFS are less trusting of Oranga Tamariki as a ministry.

The work done by Lennox et al. (2012) in establishing a model of information-sharing for adult prisoners in the United Kingdom is reflected in this current research project. Lennox et al. (2012) identified that prison staff want information about mental health history, while mental health staff want information about risk and sentences. Their finding (that mental health teams usually received more information than the prison staff received) was similar to the current findings. Most case leader teams wanted more information from YFS, but they also wanted that information to be more appropriate to the youth justice residence setting. Overall, YFS teams reported satisfaction with the information received from case leaders, on the basis that they received most of the information that case leaders had available to them. The identified issue was a lack of Oranga Tamariki information available to the case leaders upon a young person's admission to residence. YFS teams usually proceeded with assessments, however, often the information gathering and dissemination occurred after 
the assessment had been completed by YFS. This highlights systemic information-sharing issues within Oranga Tamariki, where there is a lack of quick access to relevant Oranga Tamariki information to case leaders, despite working within that sector and having a shared database. There are also issues of poor information flow between the various YFS teams, although this is compounded by the lack of a national shared mental health database.

While the findings of this research project align with both policy and literature about information-sharing, it is also clear that the existing policies and literature do not provide the specificity required for this particular field of practice. The theme of specialised work in the youth justice residential environment was apparent across the focus group data. This research project is the first of its kind, and hopefully will be used as a catalyst for further crosssector information-sharing policy and practice clarification.

While the literature about cross-sector information-sharing focused on the tensions between sectors (Richardson \& Asthana, 2006; Rothi \& Leavey, 2006), this research project offered a different focus. It seems that case leaders and YFS clinicians generally operate within similar frameworks of clinical understanding; however, the tension arises from competing frameworks within youth justice residences. The Office of the Children's Commissioner (2015) report identified tensions between containment and therapeutic models within youth justice residences. This was supported by the report into youth justice residences that suggested one overarching framework for the residence (Lambie et al., 2016). Instead of thinking about navigating organisational culture issues between the two sectors, this research project has highlighted that the careful navigation occurs within the residence, between case leaders and the other residential staff. The organisational cultural tensions tend to occur between different staff groups within youth justice residences, rather than between case leaders and YFS clinicians. The tensions are intra-sectoral rather than cross-sectoral.

\section{Moving forward}

This research highlighted some areas for improvement for both Oranga Tamariki and youth forensic teams, as well as raising concerns about how young offenders can access mental health care in the community. A number of practice recommendations were made, and improvements have started to be implemented. The issues of youth forensic connectedness and working with community mental health teams are discussed below, followed by a proposed model of information-sharing.

\section{Youth forensic forum}

The Ministry of Health (2011) prepared a document about YFS workforce development, with many recommendations that have already been implemented, with one notable exception. During the data-collection phase of this research in 2017, there had been no progress made about the recommendation for a national youth forensic forum to pull the workforce together and share expertise. The findings of the research project highlighted a clear need for this, with a lack of existing relationship between YFS teams. One of the results of this research project was a gathering of momentum among the YFS workforce for a national forum. This culminated in the inaugural national youth forensic forum in Auckland in October 2018. The forum was marae-based, with a focus on whakawhānaungatanga. It resulted in commitment from the workforce for annual national YFS forums.

\section{CAMHS}

YFS teams expressed frustration with the low levels of client retention within community CAMHS teams for young people who have offended, which they attributed to the model 
of care utilised by CAMHS. General CAMHS teams are not funded to provide assertive outreach services. However, there is a wealth of literature showing the positive effects of this approach for "difficult to engage" young people (French, Reardon, \& Smith, 2003; Schley, Yuen, Fletcher, \& Radovini, 2012). Naylor, Lincoln, and Goddard (2008), in their review of a specialist mental health service for young offenders in the United Kingdom, found that flexibility and outreach appointments helped those young people to engage in the service. Given the significant mental health issue prevalence rates among this population (The Werry Centre, 2009), and the structural, cultural and practical barriers to engagement in traditional CAMHS (Appleby \& Phillips, 2013), investing in assertive outreach approaches within CAMHS is important. There have been outreach approaches initiated in some CAMHS, with plans for expansion into further geographical areas of need. This remains an under- researched area of practice, underpinned by strong social work values and a commitment to making services responsive to the needs of the people they serves.

\section{Proposed model of information-sharing}

Collating all the findings about what each sector would like, and the factors that enhance information-sharing, the researcher has developed a model of informationsharing in youth justice residences, as depicted below. The model has been developed based on the feedback from case leaders and YFS clinicians. It has not been reviewed by the Privacy Commissioner, and is based on the assumption that a young person consents to information-sharing between case leaders and YFS clinicians, which happens for the majority of cases. However, difficulties arise when a young person does not consent to their information being shared.

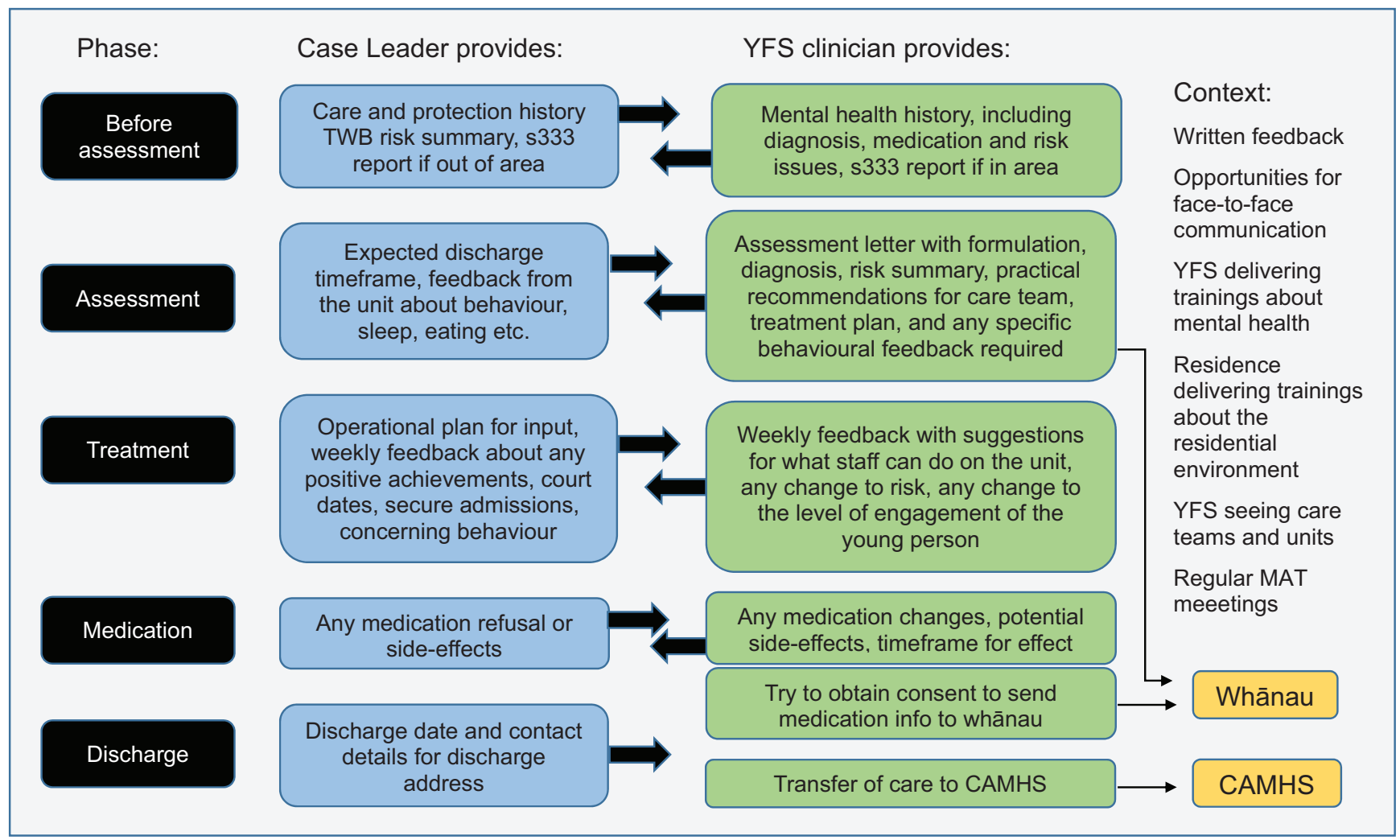

Figure 1. Information-sharing model. 


\section{Conclusion}

Cross-sector information-sharing about young people in youth justice residences is important due to the high rate of mental health issues among this population, the multitude of professionals involved, and the risk issues associated with residence life. The aim of this research project was to explore the views of youth justice residence case leaders and YFS clinicians regarding sharing information about young people with mental health needs. An additional purpose was to identify ways to improve informationsharing with shared expectations across the two sectors, with the development of an information-sharing model specifically for this context.

The overall impression was that case leaders and YFS clinicians are a committed group of professionals, enjoying the challenge of working with young people in residence, and working hard to improve outcomes for this population. The literature strongly suggests that effective, cross-sector information-sharing is difficult to achieve in practice, and yet these teams have navigated this complex issue without any informationsharing guidelines for youth justice residences.

Cross-sector information-sharing appears to be working well currently, although there is room for improvement. This research project has provided the first chance to explore the information-sharing expectations of each sector from a national perspective. The next steps are to look at what is possible within the Aotearoa New Zealand legal framework, and get clearer policy to support this specialised workforce.

Effective information-sharing between professionals occurs in contexts of positive relationships, where roles are clear, there is understanding of the other sector, and clear processes are in place. Making the proposed information-sharing model a reality would depend on these four factors being present, and would require input from the Privacy
Commissioner, as well as sign-off from the eight services (each residence and YFS team).

One of the limitations of this research was that the experiences of only case leaders and YFS clinicians were included. There is scope for further research to capture the experience of the many young people being assessed in the youth justice sector, and to identify what is most meaningful for them. This would be a major study requiring funding for further focus groups and/or individual interviews with young people.

Many of the research participants were social workers, particularly from Oranga Tamariki. Social work principles of advocacy, collaboration, and use of a systemic lens are all relevant to the topic of information-sharing. Social workers have a role in leading collaborative efforts, using our skills to navigate cross-sector relationship-building. In this context, information is shared about a severely disenfranchised group of young people. It is important to get this right so that these young people receive excellent care from all services involved with them.

\section{Acknowledgements}

This research project received funding from the A+ Trust and the Māori Education Trust. The first author is employed by Auckland District Health Board in one of the teams that participated in this research project. The authors acknowledge the contribution of eight teams that participated in this research project.

\section{References}

Agranoff, R., \& McGuire, M. (2001). Big questions in public network management research. Journal of Public Administration Research and Theory, 11(3), 295-326.

Anderson, C. (2005). The integrated children's system: challenges of information sharing. Paediatric Nursing, 17(10), 34-36.

Appleby, J., \& Phillips, D. (2013). Enhancing engagement in CAMHS. Aotearoa New Zealand Social Work, 25(1), 24-34.

Bai, Y., Wells, R., \& Hillemeier, M. M. (2009). Coordination between child welfare agencies and mental health service providers, children's service use, and outcomes. Child Abuse and Neglect, 33, 372-381. 
Braun, V., \& Clarke, V. (2006). Using thematic analysis in psychology. Qualitative Research in Psychology, 3(2), 77-101

Cameron, A., \& Lart, R. (2003). Factors promoting and obstacles hindering joint working: A systematic review of the research evidence. Journal of Integrated Care, 11(2), 9-17.

Daley, D. M. (2009). Interdisciplinary problems and agency boundaries: Exploring cross agency collaboration. Journal of Public Administration Research and Theory, 19(3), 477-493.

Darlington, Y., Feeney, J. A. \& Rixon, K. (2004). Complexity, conflict and uncertainty: Issues in collaboration between child protection and mental health services. Children and Youth Services Review, 26, 1175-1192.

Davidson, C., \& Tolich, M. (Eds.). (2003). Social science research in New Zealand: Many paths to understanding (2nd ed.). Auckland, New Zealand: Pearson.

French, R., Reardon, M., \& Smith, P. (2003). Engaging with a mental health service: Perspectives of at-risk youth. Child and Adolescent Social Work Journal, 20(6), 529-548.

Gask, L. (2005). Overt and covert barriers to the integration of primary and specialist mental health care. Social Science \& Medicine, 61, 1785-1794.

Gil-Garcia, J. R., \& Sayogo, D. S. (2016). Government inter-organisational information sharing initiatives: Understanding the main determinants of success. Government Information Quarterly, 33, 572-582.

Haight, W. L., Bidwell, L. N., Marshall, J. M., \& Khatiwoda, P. (2014). Implementing the crossover youth practice model in diverse contexts: Child welfare and juvenile justice professionals' experiences of multisystem collaborations. Children and Youth Services Review, 39, 91-100.

Jones, B. L. (2016). Offending outcomes for Māori and non-Māori, an investigation of ethnic bias in the criminal justice system: Evidence from a New Zealand birth cohort (Unpublished Master's thesis). University of Canterbury, Christchurch, New Zealand.

Lambie, I., Krynen, A., \& Best, C. (2016). Youth justice secure residences: A report on the international evidence to guide best practice and service delivery. Wellington, New Zealand: Ministry of Social Development.

Laming, L. (2003). The Victoria Climbié inquiry: Report of an inquiry by Lord Laming. London, United Kingdom: The Stationery Office.

Lennox, C., Mason, J., McDonnell, S., Shaw, J., \& Senior, J. (2012). Information sharing between the National Health Service and criminal justice system in the United Kingdom. Journal of Forensic Nursing, 8, 131-137.

Lunt, N. T., Ramian, K., Shaw, I., Fouché, C., \& Mitchell, F. (2012). Networking practitioner research: Synthesising the state of the "art". European Journal of Social Work, 15(2), 185-203.

Lynch, N. (2016). Neurodisability in the Youth Justice System in New Zealand: How vulnerability intersects with justice. Retrieved from https://papers.ssrn.com/sol3/papers. cfm?abstract_id=2869502.

McArdle, S., \& Lambie, I. (2018). Screening for mental health needs of New Zealand youth in secure care facilities using the MAYSI-2. Criminal Behaviour and Mental Health, 28, 239-254.
Mills, A., Meek, R., \& Gojkovic, D. (2012). Partners, guests or competitors: Relationships between criminal justice and third sector staff in prisons. Probation Journal, 59(4), 391-405.

Ministry of Health. (2011). Youth forensic services development: Guidance for the health and disability sector on the development of specialist forensic mental health, alcohol and other drug, and intellectual disability services for young people involved in New Zealand's justice system. Wellington, New Zealand: Author.

Ministry of Social Development. (2016). Kids in care National and local level data. Retrieved from http://www.cyf.govt.nz/about-us/key-statistics/kids-in-care.html

National Research and Evaluation Unit. (2013). Information sharing between government agencies: Cultural perspectives. Wellington, New Zealand: Inland Revenue Department.

Naylor, C., Lincoln, J., \& Goddard, N. (2008). Young people at risk of offending: Their views on a specialist mental health service in south east London. Clinical Child Psychology and Psychiatry, 13(2), 277-286.

Office of the Children's Commissioner. (2015). State of care 2015: What we learnt from monitoring Child, Youth and Family. Wellington, New Zealand: Author.

Office of the Prime Minister's Chief Science Advisor. (2018). It's never too early, never too late: A discussion paper on preventing youth offending in New Zealand. Retrieved from www.pmcsa.org.nz

Richardson, S., \& Asthana, S. (2006). Inter-agency information sharing in health and social care services: The role of professional culture. British Journal of Social Work, 36, 657-669.

Rothi, D., \& Leavey, G. (2006). Child and adolescent mental health services (CAMHS) and schools: Inter-agency collaboration and communication. The Journal of Mental Health Training, Education and Practice, 1(3), 32-40.

Schley, C., Yuen, K., Fletcher, K., \& Radovini, A. (2012). Does engagement with an intensive outreach service predict better treatment outcomes in "high-risk" youth? Early Intervention in Psychiatry, 6(2), 176-184.

Shaw, I., \& Lunt, N. (2001). Navigating practitioner research. British Journal of Social Work, 41, 1548-1565.

Siraj-Blatchford, I., \& Siraj-Blatchford, J. (2010). Improving developmental outcomes for children through effective practice in integrating early years services. London, England: Centre for Excellence and Outcomes in Children and Young People's Services.

Skowyra, K. R., \& Cocozza, J. J. (2007). Blueprint for change: A comprehensive model of the identification and treatment of youth with mental health needs in contact with the juvenile justice system. New York, NY: Office of Juvenile Justice and Delinquency Prevention.

The Werry Centre. (2009). A literature review: Mental health and alcohol and other drug screening, assessment and treatment for youth justice populations. Retrieved from http://www.werryworkforce.org/professionals/ publications-and-resources?tid=All\&tid_1=All\&tid_2=All\& field_released_date_value[value]\&page $=2$.

Wilson, L. S., Pillay, D., Kelly, B. D., \& Casey, P. (2015). Mental health professionals and information sharing: Carer perspectives. Irish Journal of Medical Science, 184(4), 781-790. 